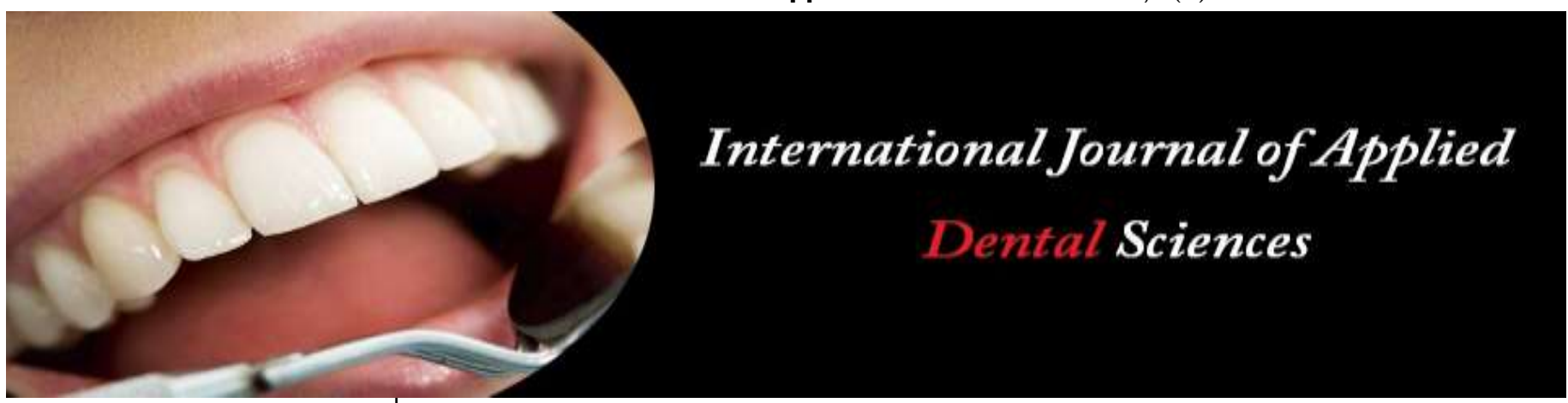

ISSN Print: 2394-7489

ISSN Online: 2394-7497

IJADS 2021; 7(2): 178-182

(C) 2021 IJADS

www.oraljournal.com

Received: 23-01-2021

Accepted: 07-03-2021

Dr. Claudia Peter

PG Students, Department of

Prosthodontics, Sree Mookambika

Institute of Dental Science,

Kulasekaram, Kanyakumari,

Tamil Nadu, India

\section{Dr. Harshini}

PG Students, Department of

Prosthodontics, Sree Mookambika

Institute of Dental Science,

Kulasekaram, Kanyakumari,

Tamil Nadu, India

\section{Dr. T Sreelal}

Former Head of the Department and Honourable Professor,

Department of Prosthodontics,

Sree Mookambika Institute of

Dental Science, Kulasekaram,

Kanyakumari, Tamil Nadu, India

\section{Dr. Aparna Mohan}

Reader, Department of

Prosthodontics, Sree Mookambika

Institute of Dental Science,

Kulasekaram, Kanyakumari,

Tamil Nadu, India

Dr. Allen Jim Hines

Reader, Department of

Prosthodontics, Sree Mookambika

Institute of Dental Science,

Kulasekaram, Kanyakumari,

Tamil Nadu, India

\section{Dr. TC Giri}

Professor, Department of Prosthodontics, Sree Mookambika Institute of Dental Science, Kulasekaram, Kanyakumari, Tamil Nadu, India

\section{Management of temporomandibular disorder in a completely edentulous patient with tens guided complete denture: A case report}

\author{
Dr. Claudia Peter, Dr. Harshini, Dr. T Sreelal, Dr. Aparna Mohan, Dr. \\ Allen Jim Hines and Dr. TC Giri
}

DOI: $\underline{\text { https://doi.org/10.22271/oral.2021.v7.i2c.1207 }}$

\begin{abstract}
Pain is an unpleasant experience, which can hinder normal quality of life. This pain when further combined with debilitating conditions such as completely missing teeth becomes a hurdle to perform normal basic functions such as mastication, phonation, swallowing, yawning and in extreme cases even hinders ability to perform normal expressions such as smiling. Thus management of such pain at the earliest together with rehabilitation to prevent future relapse should be the ultimate objective of any treatment plan. The following case report describes a treatment of a patient suffering from TMD with a TENS guided complete denture.
\end{abstract}

Keywords: Temporomandibular disorder, tens guided, quality of life

\section{Introduction}

Long term success of any dental treatment requires a relaxed and balanced muscular coordination ${ }^{[1]}$. Transcutaneous electrical nerve stimulation (TENS) therapy involves the use of low-voltage electric currents to treat persistent pain. A small device is used to deliver the current at or near nerves. TENS therapy works by blocking pain or changing the perception of pain ${ }^{[2]}$.

TENS is commonly used by health professionals for acute and chronic pain management. In dentistry, though TENS has potential applications ${ }^{[4]}$.

The main purpose for ULF TENS is to help the dentist determine a more optimal mandibular jaw position when recording a physiologic maxillo-mandibular inter occlusal jaw registration. Having the spastic muscles relaxed prior to recording a bite registration is therapeutically and clinically beneficial rather than trying to record a bite registration with hyperactive and strained muscles.

\section{Uses ULF TENS in dentistry}

- To treat temporomandibular joint (TMD) dysfunctions and associated pain.

- To relieve symptoms associated with muscle spasm.

- To relax muscles and establish a physiologic occlusion.

- To take an occlusal registration.

- To take denture impressions.

- To increase local blood circulation

- To maintain or increase mandibular range of motion ${ }^{[1,3]}$.

The following case report presents a method in which temporomandibular disorder in a completely edentulous patient was treated with complete denture fabricated with TENS.

\section{Case report}

A 82 year old female patient reported to the department of Prosthodontics, crown and bridge, Sree Mookambika Institute of Dental Sciences, Kulasekaharm, Kanyakumari with a chief 
complaint of difficulty on chewing due to pain on the left side of the face while opening and closing of mouth. Patient was a complete denture wearer for past 14 years, denture showed completely worn out occlusal surface and lost vertical dimension [Figure 1]. Her dental history revealed that she had a locked jaw while yawning and forcefully attempted to close resulting in pain for the past one week day. Intraoral examination revealed completely edentulous upper and lower arches. Further examination of TMJ revealed presence clicking and popping sounds while opening and closing and tenderness on both sides during palpation. Based on the above features and further radiographic investigations with CBCT [Figure 2] patient was diagnosed with anterior disc displacement with reduction. Treatment plan for the present case was new denture fabrication with Transcutaneous electrical nerve stimulation (TENS) guidance.
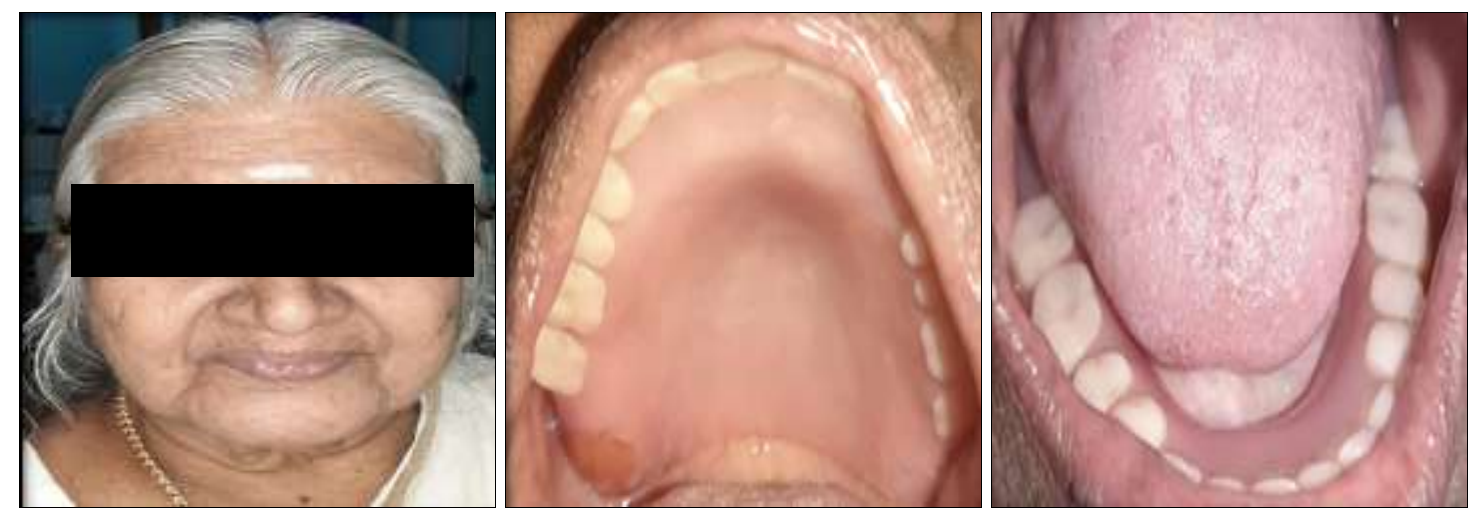

Fig 1: Pre-operative, old denture
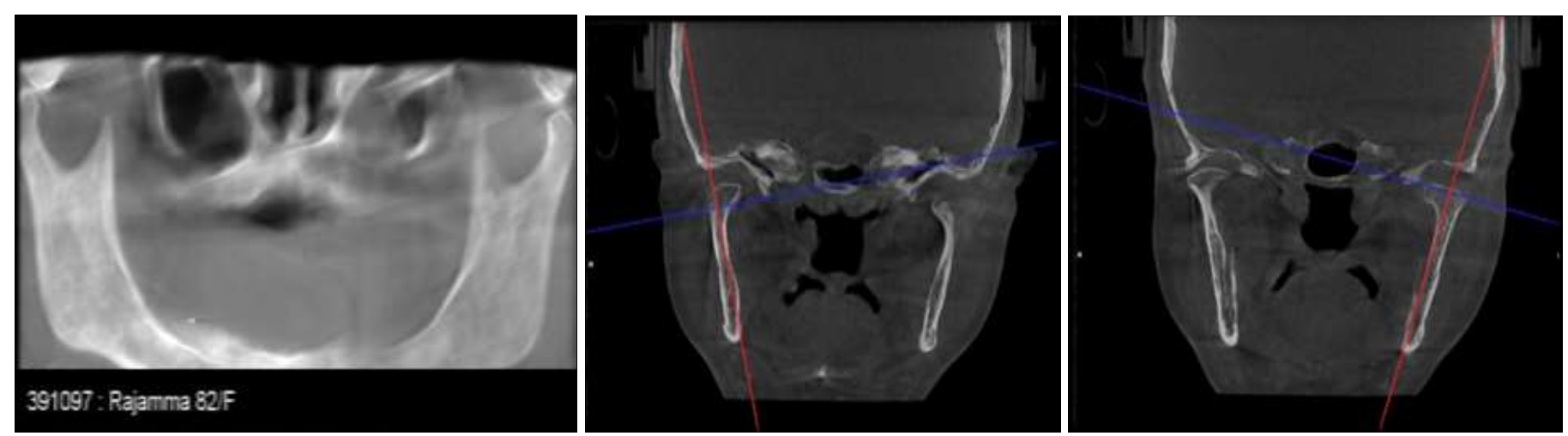

Fig 2: Radiographic images; CBCT

First before initiation of prosthodontics management an Ultralow frequency TENS (J5 myo-monitor) was done for about 40 minutes to reduce pain followed by which the patient had significant relief of pain [FIGURE 3]. Followed by which upper and lower primary impression was made with condensation silicone putty and lined with light body condensation silicone (Zhenmark) [Figure 4].

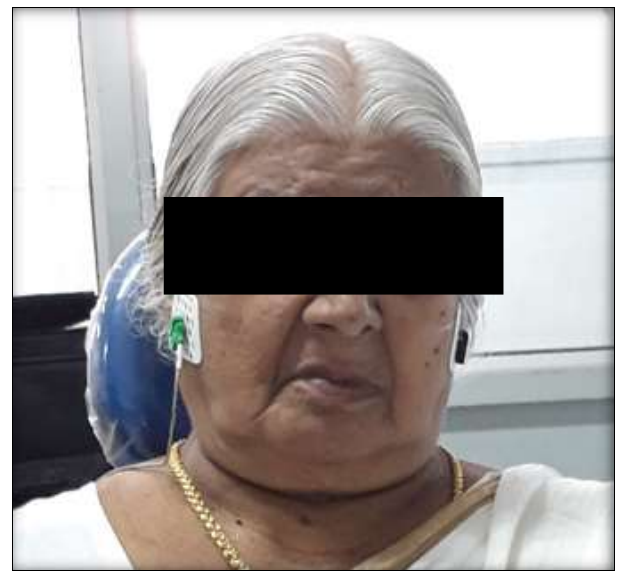

Fig 3: Ulf tens for 40 mins

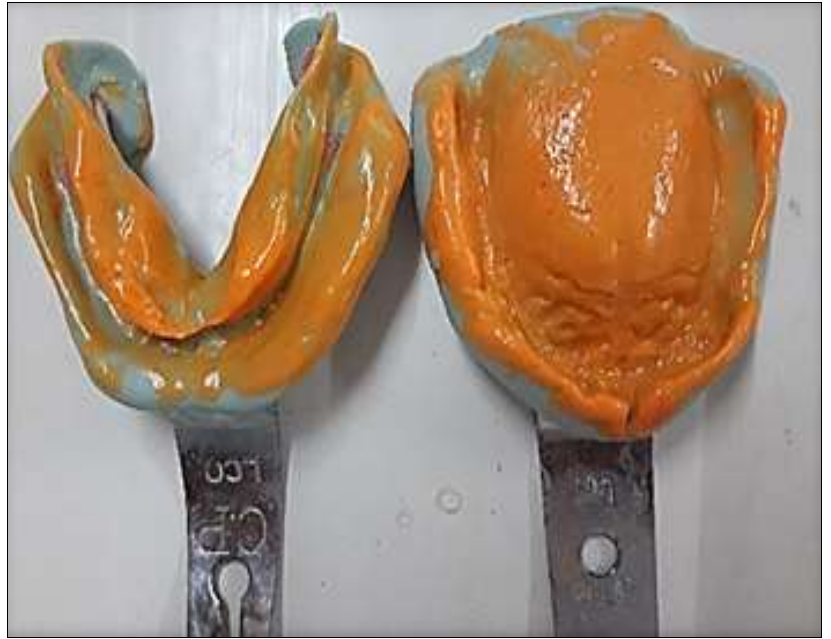

Fig 4: Primary impression

The next step was secondary impression making in which custom trays for upper and lower casts were made, border moulding was done using low fusing impression compound (DPI Pinnacle) and wash impression was made with light boby condensation silicone (Zhenmark) [Figure 5]. 

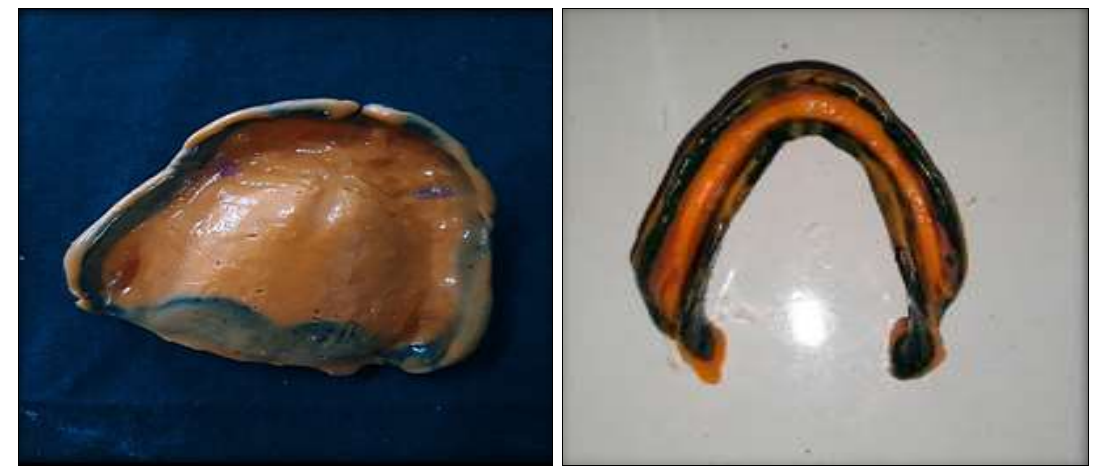

Fig 5: Secondary impression

In the next appointment tentative jaw relation was recorded with guidance of TENS. Fist the upper occlusal rim was inserted and adjusted to obtain proper lip support and incisal visibility followed by which occlusal plane was made parallel to campers plane. Then lower occusal rim was inserted and a ultralow frequency TENS (J5

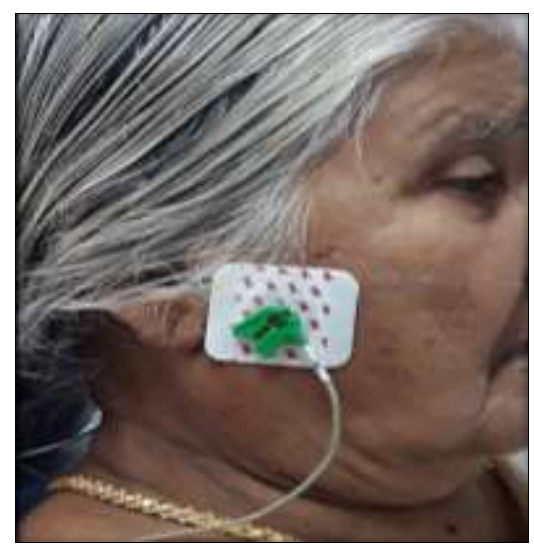

Fig 6: Tens to record maxillomandibular relation myo-monitor) graduated from 0 to $20 \mathrm{~mA}$ (the maximum amount the patient was able to tolerate) was applied for 30 minutes to guide the jaws into most comfortable neuromuscular position [Figure 6]. This maxillomandibular relation [Figure 7] was recorded in which articulation and teeth setting was done [Figure 8].

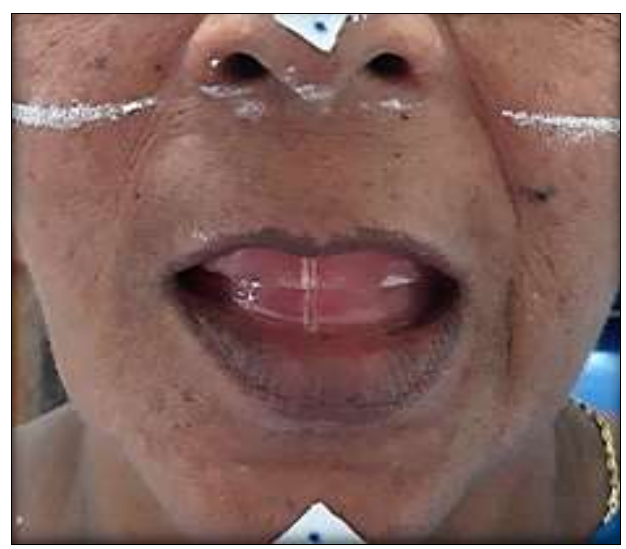

Fig 7: Final recorded maxillomandibular relation
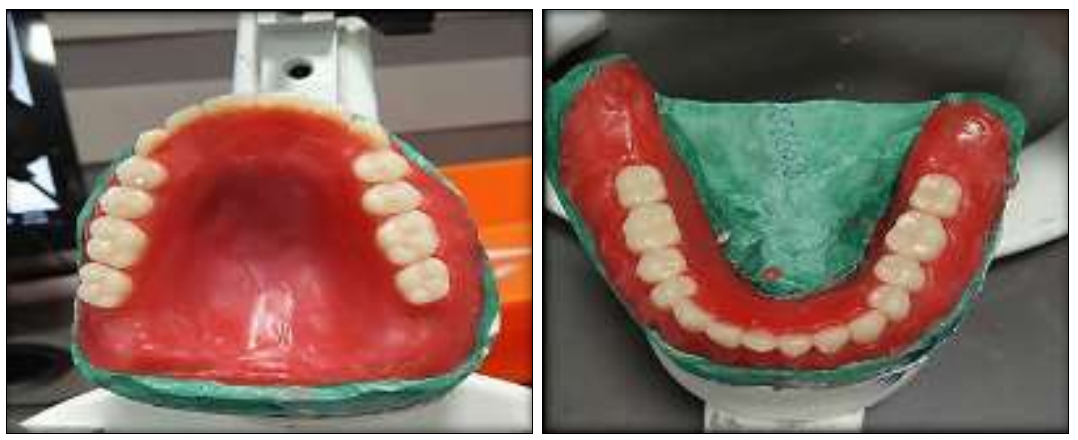

Fig 8: Teeth setting in articulator

In the next appointment try-in was to confirm the maxillomandibular relation in harmonious neuromuscular position [Figure 9].

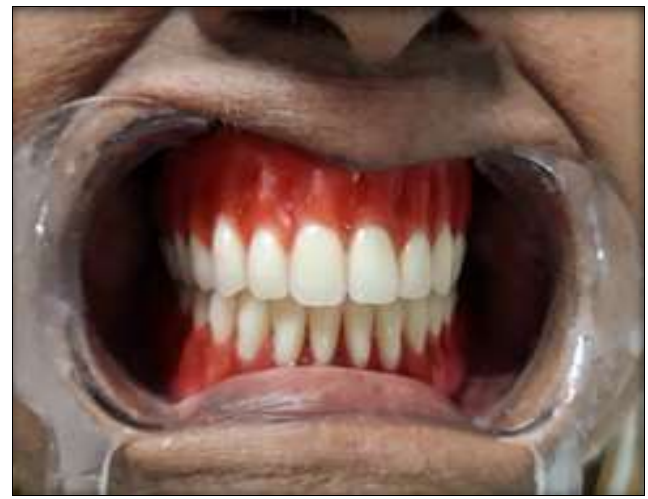

Fig 9: Wax try in

$\sim 180 \sim$ 
Followed by acrylization done using injection moulding technique [Figure 10] and final denture was inserted [Figure 11, 12]. Follow up appointments showed relief of pain and patient could open and close jaws without difficulty.

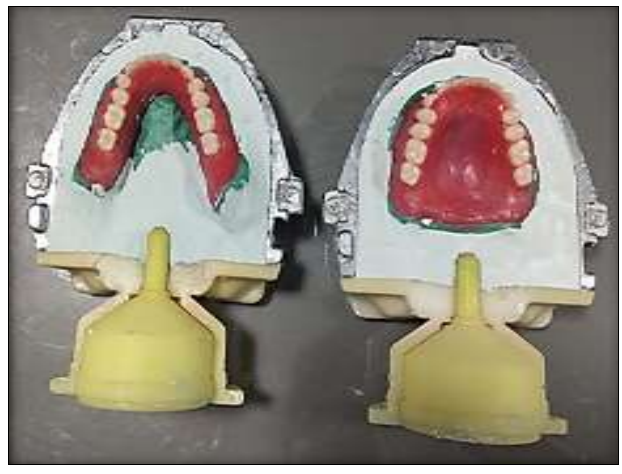

Fig 10: Injection moulding technique

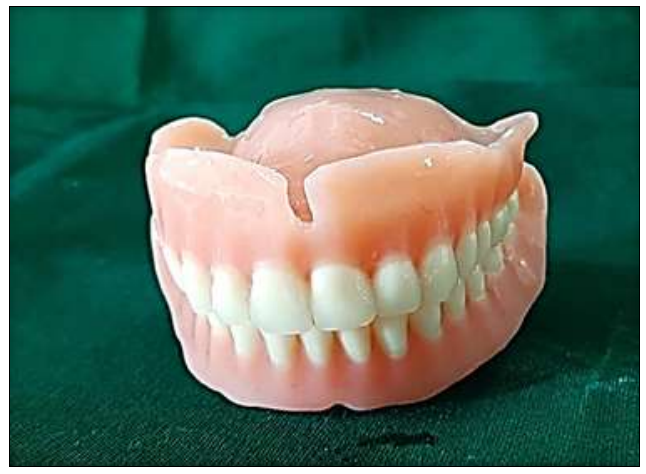

Fig 11: Final denture
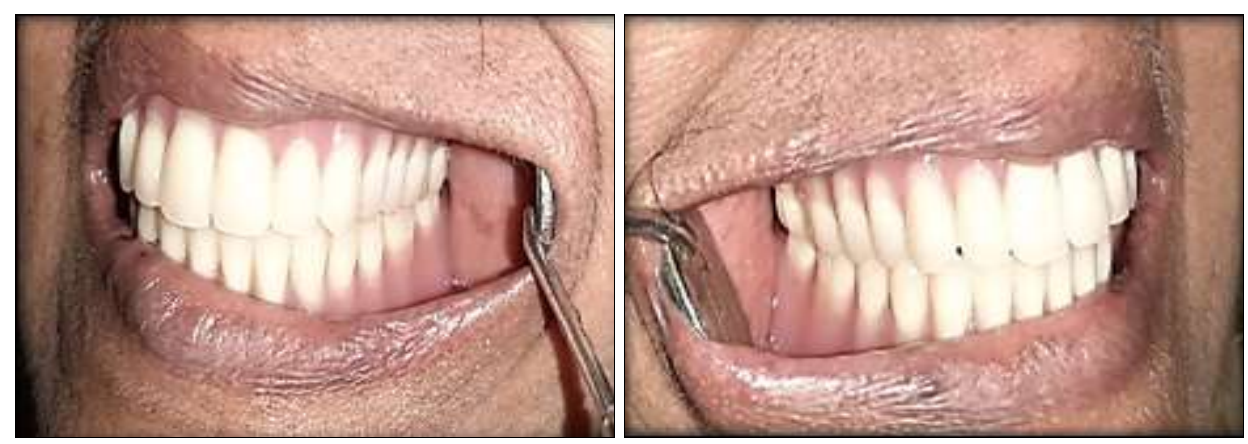

Fig 12: Denture occlusion; right lateral and left lateral views

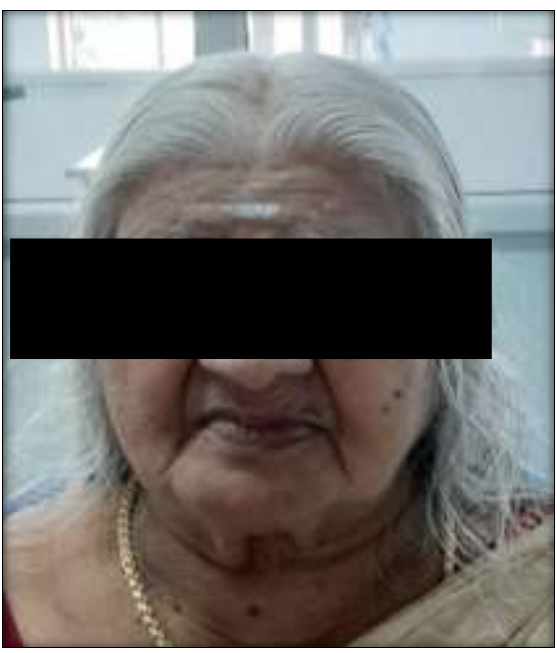

Fig 13A

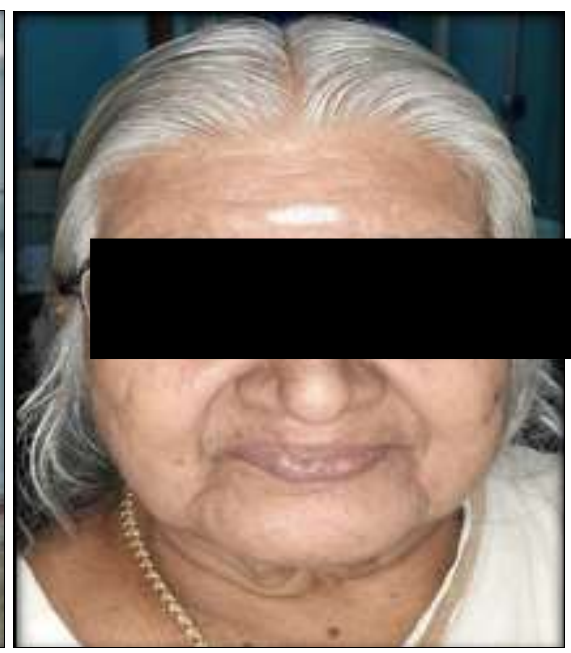

Fig 13B

Fig 13: Pre-operative (A)- without denture; (B)- with old denture

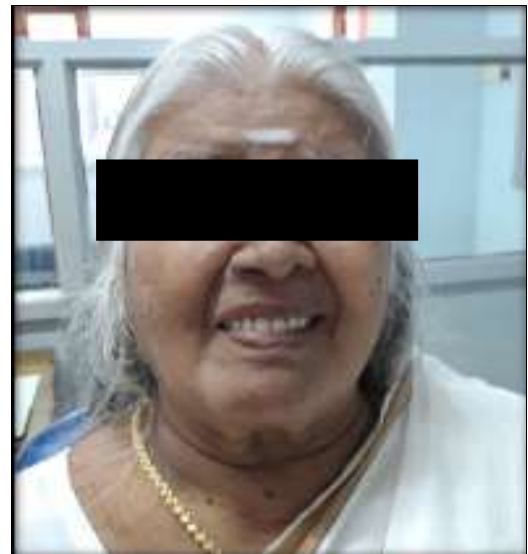

Fig 14: Post-operative-new denture

\section{Discussion}

TENS has broad applications in medicine. Both Physicians and dentists have accepted the ease, efficacy, and lack of undesirable side effects of the therapy. TENS therapy used at an early stage of the pain cycle helps to either reduce or entirely prevent development of problems which are part of progressive pain ${ }^{[1,5]}$.

Pain of the head and neck can be due to headache, toothache, trigeminal neuralgia, and TMJ syndrome. The successful application of TENS depends on the definitive location of pain. To treat TMJ associated pain electrodes have to be placed anterior to and at the level of the ear. Usually a low frequency current is applied to the head and neck region to make it more tolerableto the patient, therefore it is recommended as an adjunctive therapy together with other 
definitive therapy. This includes TMJ-joint mobilization, postural exercises, relaxation training, mandibular appliance etc. These patients may need to use TENS until such an appliance can be obtained ${ }^{[5]}$.

In this present case TENS therapy was provided until a new denture was farbricated and additionally the maxillomandibular relation was recorded in the most favourable neuromuscular position determined by TENS, so that patient could maximum relief from pain and have a harmonious occlusion with the stomatognathic system.

\section{Conclusion}

TENS can be used for pain relief during various dental procedures. Its non-pharmacological analgesic effect can be used in the management of a variety of conditions affecting maxillofacial region especially in elderly individuals in which pharmacological methods might be less preferred due to potential side effects and unwanted interactions with other medications.

\section{References}

1. Kasat V, Gupta A, Ladda R, Kathariya M, Saluja H, Farooqui AA. Transcutaneous electric nerve stimulation (TENS) in dentistry- A review. J Clin Exp Dent 2014;6(5):e562-8.

2. Raybin NH. The polished surface of complete dentures. The Journal of Prosthetic Dentistry 1963;13(2):236-239.

3. Banerjee G, Johnson MI. Transcutaneous electrical nerve stimulation (TENS): A potential intervention for pain management in India? Indian J Pain 2013;27:132-41.

4. Nilesh SB. Rehablitation of completely edentulous patient using TENS for border moulding and cheek plumbers for esthetics. Intl J Prosthet Dent 2013.

5. Katch EM. Applications of Transcutaneous Electrical Nerve Stimulation in Dentistry. Anesthesia progress 1986, 156-160. 